\title{
Litiasis en ureterocele
}

\author{
Álvarez Múgica M*, Jalón Monzón A*, González Álvarez RC*, Bulnes Vázquez V**, \\ Escaf Barmadahn S*, Fernández Gómez JM*.
}

*Servicio de Urología I. **Servicio de Radiodiagnóstico I. Hospital Universitario Central de Asturias. Oviedo.

$\mathbf{M}$ ujer de 74 años, sin antecedentes urológicos previos, ingresada de urgencia por cuadro de cólico renoureteral izquierdo complicado, por lo que se realizó un scanner de urgencia (Fig. 1) que evidenció un gran cálculo en uréter distal izquierdo, procediéndose a colocación de nefrostomía izquierda. Tras superar la fase aguda, se le realizó una pielografía descendente a través del catéter de nefrostomía, observándose un cálculo de $2,2 \mathrm{~cm}$ en el interior de un ureterocele izquierdo (Fig. 2).

Para la resolución del cuadro se procedió a la extracción de la litiasis mediante cirugía endoscópica (Figs. 3 y 4).

Dr. M. Álvarez Múgica

Servicio de Urología I.

Hospital Universitario Central de Asturias

Celestino Villamil, s/n

33006 Oviedo (Asturias)

E-mail: malvarez79@mixmail.com

(Trabajo recibido el 27 de julio 2005)

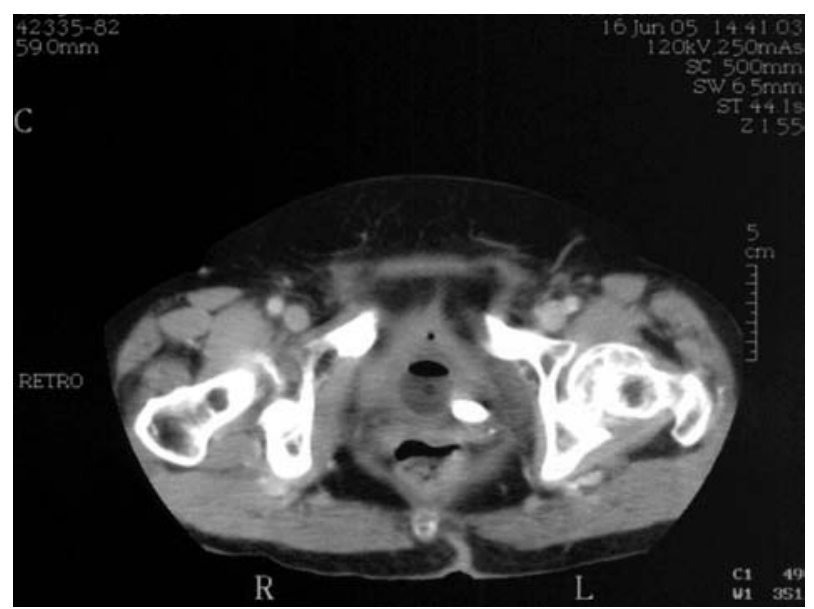

FIGURA 1. Excisión endoscópica sobre ureterocele y extracción de litiasis de su interior.

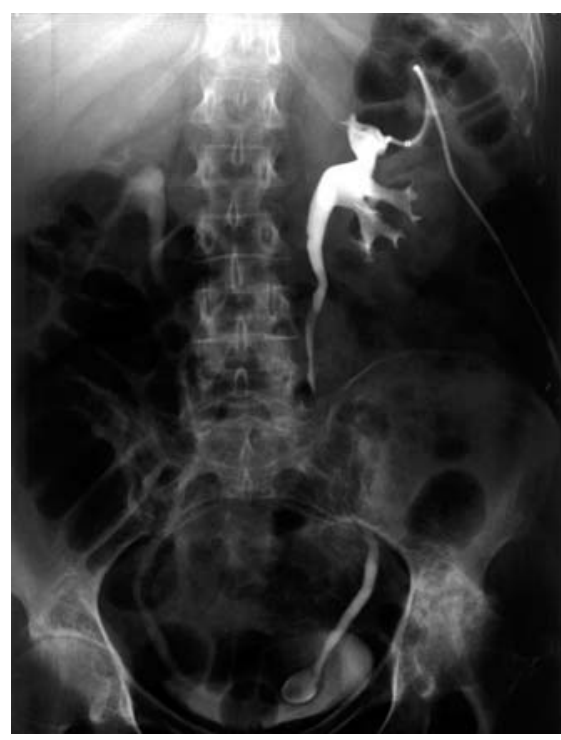

FIGURA 2. UIV: imagen en

"cabeza cobra" con cálculo en

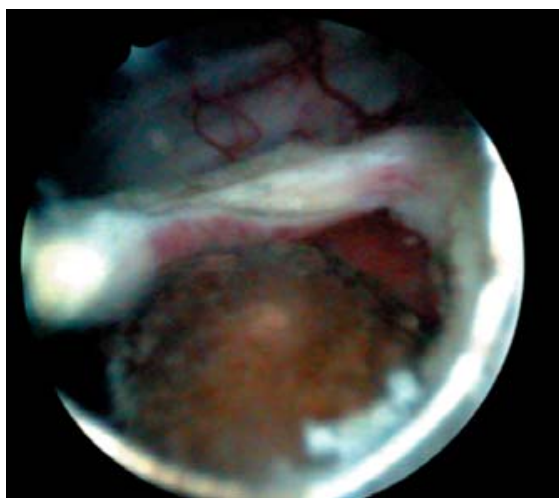
su interior.

FIGURA 3. Excisión endoscópica sobre ureterocele $y$ extracción de litiasis de su interior.

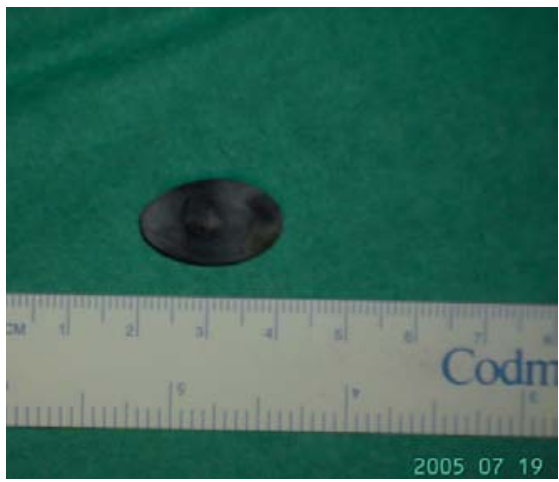

FIGURA 4.

Litiasis de 2,2 cm extraida. 